\title{
The Evaluation of Laparoscopic Port Site Complications-A Descriptive Type of Study
}

\author{
Iqbal Masud Khan ${ }^{1}$, Md. Zakir Hossain ${ }^{2}$, Nishat Farhana Khan $^{3}$, Nabaneeta Sarker ${ }^{4}$, Nayeem ${ }^{5}$
}

\author{
${ }^{1}$ Associate Professor, Dept. Of Gastro Intestinal Laparoscopic Onco Surgery, MBBS, MS, MARKS Medical College \& Hospital, Dhaka, Bangladesh \\ ${ }^{2}$ Associate Professor and Classified Specialist, Dept. of Otolaryngology-Head \& Neck Surgery, MBBS, MCPS, DLO, FCPS, FACS (USA), FRCS \\ (Glasg), Central Medical Board and Combined Military Hospital, Dhaka Cantonment, Dhaka-1206, Bangladesh \\ ${ }^{3}$ Associate Professor, Dept. Of Head (Community Medicine), MARKS Medical College \& Hospital, Dhaka, Bangladesh \\ ${ }^{4}$ Clinical Assistant, Dept. Of Surgery, MARKS Medical College \& Hospital, Dhaka, Bangladesh \\ ${ }^{5}$ Registrar, Dept. Of Surgery, MARKS Medical College \& Hospital, Dhaka, Bangladesh
}

Introduction: Laparoscopic surgery is the standard care for many surgical and gynecological conditions with documented benefits and excellent outcome. The main reason for preference of laparoscopic surgeries to abdominal surgeries are being performed laparoscopically as a result of advancement in medical science. Objective: An Evaluation of laparoscopic port site complications in a Marks Medical College \& Hospital, Dhaka, Bangladesh. Methods and Materials: We carried out a descriptive type of study in the Dept. Of Gastro Intestinal Laparoscopic Onco Surgery, Marks Medical College \& Hospital, Dhaka, Bangladesh during the period from January 1, 2017 to December 31, 2018. Our aim was to evaluate the laparoscopic port site complication in Bangladesh. Laparoscopic techniques have revolutionized the field of surgery and offer several advantages over laparotomy including lower patient morbidity rates, reduced hospital length of stay and earlier return to normal activities. Although rare, several port site complications have been reported in the literature. Laparoscopic port site complications can be access-related or post-operative. Complications are related to port-site incision size, number of port sites, obesity, and umbilical ports. Results: A total of 200 cases were selected for this study. Of the 200 patients undergoing laparoscopic surgery, Majority $(60.00 \%)$ of cases were female and $(40.00 \%)$ were male. $(30.00 \%)$ were aged between $<20$ years, $(29.00 \%)$ were aged between from $31-40$ and $>41$ were $(41.00 \%)$ years. Majority $(2.50 \%)$ of cases were in port site discharge, $(1.00 \%)$ were in port site TB, port site incisional hernia was $(0.50 \%)$, port site bleeding was $(1.00 \%)$ and the port site metastasis were $(0.50 \%)$. Laparoscopy offers advantage of rapid postop recovery. It is recommended to follow proper technique of sterilization of laparoscopic instruments to prevent PSI. Infection is most commonly seen at port site through which gall bladder was extracted. Conclusion: Complications encountered at port site were discharge, infection, bleeding, port site hernia and metastasis with discharge and infection being most common.

Key words: Laparoscopic, Complications, Surgery, Laparotomy, Particle Size Discharge (PSD).

Copyright @ 2020: This is an open-access article distributed under the terms of the Creative Commons Attribution license which permits unrestricted use, distribution, and reproduction in any medium for non-commercial use (NonCommercial, or CC-BY-NC) provided the original author and source are credited.

\section{INTRODUCTION}

Laparoscopic surgery is the standard care for many surgical and gynecological conditions with documented benefits and excellent outcome. The main reason for preference of laparoscopic surgeries to abdominal surgeries is being performed laparoscopically as a result of advancement in medical science. However, these complications are by far very rare. The overall rate of major complications following a laparoscopic procedure is approximately 1.4 per 1,000 procedures. However, other rare complications include pyoderma gangrenosum, metastasis at the port site following laparoscopic endo-surgery and port site infections [1]. In this context, a port site complication is defined as an infection of the skin and subcutaneous tissue at the site of portscreated during laparoscopic surgery which discharges purulent material spontaneously or is opened to drain the same by the surgeon [2]. Organisms have to be isolated from an area of infection, and the surroundings show typical signs of inflammation like pain, redness, swelling, etc. For safer surgery on the target organ and to have control on its vascular supply the surgeon has to make an incision large enough to provide the clear view of the target organ as well as its blood supply. The wound sustains additional trauma from retractors, whether metallic or human.The operative wound is cause for morbidity 
including pain, bleeding, wound infections, nerve entrapment, and herniation [3]. The post-operative pain at the wound site precludes the patient from early mobility and deep respiration especially true for upper abdominal incision. In laparoscopic surgery, the creation of pneumoperitoneum is essential for establishing a working space in which surgeon has to access the target organ and its blood supply. The pneumoperitoneum is created by the insufflation of carbon dioxide gas in the peritoneal cavity and lifting the abdominal wall gently with force being diffuse and evenly distributed resulting in minimal trauma to the abdominal wall $[4,5]$. The patient experiences less pain and other wound-related complications. Even when there is port site infection, it is far less in severity and easily controlled by local means in the majority of cases. Wound disruption and herniation are far less if the Z-technique is used during insertion of trocar and cannula and if proper port site closure is employed primarily in $10 \mathrm{~mm}$ port sites. However, the incidence of port site complications following laparoscopic surgery is considered to be around 21 per 100,000 cases and it has shown a proportional rise with the increase in size of the port site incision and trocar. The overall complications/injuries that occur following laparoscopic surgeries involve gastrointestinal $(0.06 \%)$, genitourinary $(0.03 \%)$, vascular $(0.01 \%)$ and omentum $(0.04 \%)[17]$. Atypical mycobacteria have been reported at the port site in the literature. Primary or secondary anti-tubercular treatment is required in such cases $[6$, 7]. Few refractory cases required debridement and excision of sinus tract followed by anti-tubercular or antibacterial treatment [8]. Minimally invasive surgeries such as laparoscopic surgeries have become the order of the day for many surgical diseases. Major complications are access related such as major vascular injury or inadvertent bowel injuries, which life is threatening, while other complications such as port site infections may occur which would need proper treatment. This study will evaluate the incidence of port site complications in Bangladesh.

\section{OBJECTIVES}

\section{a) General objective}

- An Evaluation of laparoscopic port site complications in a Marks Medical College \& Hospital, Dhaka, Bangladesh.

\section{b) Specific Objectives}

- To determine the complications associated with the port site in laparoscopic surgeries.

- To identify the risk factors of laparoscopic port site complications in Bangladesh.

\section{METHODS AND MATERIALS}

We carried out a descriptive type of study in the Dept. Of Gastro Intestinal Laparoscopic Onco Surgery, Marks Medical College \& Hospital, Dhaka, Bangladesh during the period from January 1, 2017 to December 31, 2018. We used purposive sampling method. Written informed consent was obtained from the patients before enrolling into the study. A total number of 200 patients were included in the study.

\section{Inclusion Criteria}

According to our inclusion criteria all patients of both sexes, who were $>20$ years of age and medically fit to undergo the procedure, were included in the study.

\section{Exclusion Criteria}

According to exclusion criteria patients' age, contraindication to general anaesthesiapatients with complicated inguinal hernia like obstruction, strangulation or gangrene and patients who have undergone previous lower abdominal surgeries were excluded.

\section{RESULTS}

A total of 200 patients had laparoscopic surgery during the study period. Majority $(60.00 \%)$ of cases was female and $(40.00 \%)$ were male shown in [Table -1 \& Figure-1]. In [Table-2] Age distribution of the studied participant's majority $(41 \%)$ were aged above 41 years, $(29.00 \%)$ were aged between from 31 40 and $>20$ were $(30.00 \%)$.

Table-1: Shows the Sex Distribution of the studied participants $(\mathrm{N}=\mathbf{2 0 0})$

\begin{tabular}{|l|c|c|}
\hline Gender & $\mathbf{N}$ & \% \\
\hline Male & 80 & 40.0 \\
\hline Female & 120 & 60.0 \\
\hline Total & 200 & 100.0 \\
\hline
\end{tabular}

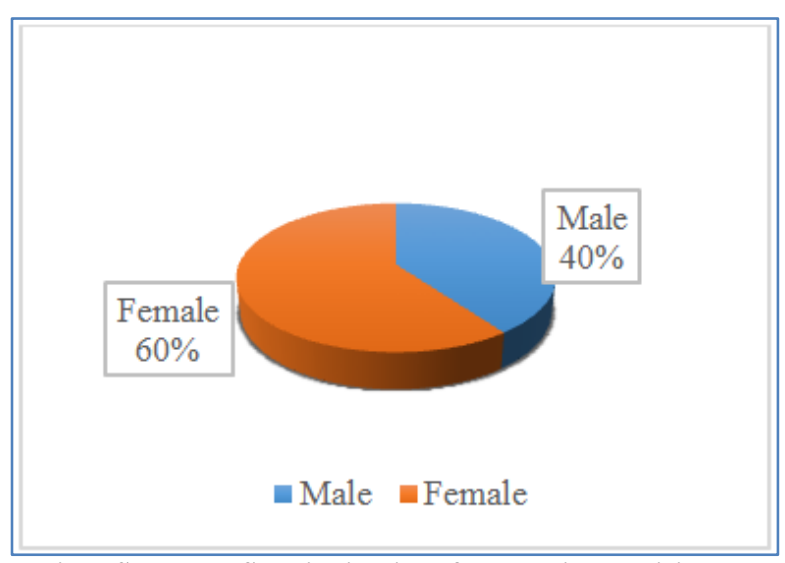

Fig-I: Shows the Sex distribution of the studied participants

Table-2: Shows the Age Distribution of the studied participants $(\mathrm{N}=\mathbf{2 0 0})$

\begin{tabular}{|c|c|c|}
\hline Age & $\mathbf{N}$ & $\mathbf{\%}$ \\
\hline >20 Yrs. & 60 & 30.0 \\
\hline 31-40 Yrs. & 58 & 29.0 \\
\hline >41 Yrs. & 82 & 41.0 \\
\hline Total & 200 & 100 \\
\hline
\end{tabular}


Table-3: Shows the types of surgeries of the study participants $(\mathrm{N}=\mathbf{2 0 0})$

\begin{tabular}{|l|l|l|}
\hline Variable & No. of surgeries & \% \\
\hline Lap Cholecystectomy & 99 & 49.50 \\
\hline Lap Appendectomy & 35 & 17.50 \\
\hline Lap. Hernioplasty & 26 & 13.00 \\
\hline Diagnostic laparoscopy & 21 & 10.50 \\
\hline Lap ovarian cystectomy & 14 & 7.00 \\
\hline Lap APR & 5 & 2.50 \\
\hline
\end{tabular}

Table-4: Shows the Port Site Complications

Distribution of the study participants $(\mathrm{N}=200)$

\begin{tabular}{|l|l|l|}
\hline Variable & No. of surgeries & $\mathbf{\%}$ \\
\hline Port site discharge & 5 & 2.50 \\
\hline Port site TB & 2 & 1.00 \\
\hline Port site incisional hernia & 1 & 0.50 \\
\hline Port site bleeding & 2 & 1.00 \\
\hline Port site metastasis & 1 & 0.50 \\
\hline
\end{tabular}

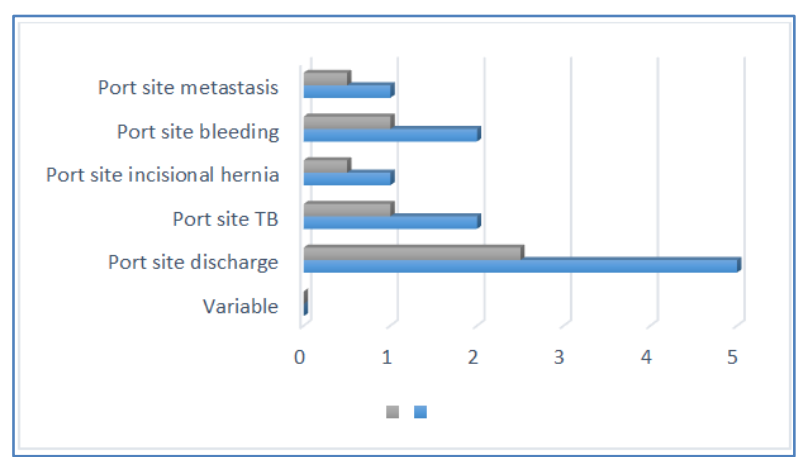

Fig-2: Shows the Port Site Complications Distribution of the study participants

[Table-3] majority (49.50\%) participants had Lap Cholecystectomy, (17.50\%) patients had Lap. Appendectomy, (13.00\%) patients had Lap. Hernioplasty, (10.50\%) patients had Diagnostic laparoscopy, $(7.00 \%)$ had Lap ovarian cystectomy and (2.50\%) patients had Lap APR. In [Table-4] shows the port site complication of the studied participants. Majority $(2.50 \%)$ of cases were in port site discharge, $(1.00 \%)$ were in port site TB, port site incisional hernia was $(0.50 \%)$, port site bleeding was $(1.00 \%)$ and the port site metastasis were $(0.50 \%)$.

\section{DISCUSSION}

There is no objection that laparoscopic surgery has had tremendous positive impact on patients and the healthcare system. Patients tend to have less pain, less morbidity and return to their daily activities more quickly. Thus, the number of laparoscopic procedures done each year continues to rise substantially. For many surgical diseases, laparoscopic surgery is the gold standard. Nevertheless, this procedure needs to be performed by experienced surgeons to avoid major complications. Just like the open surgeries, laparoscopic surgeries are also not without complications.Port site complications can be classified into access-related and postoperative complications and have been reported in both the genders and all age groups [9]. In this study Majority $(60.00 \%)$ of cases were female and (40.00\%) were male. In Age distribution of the studied participant's majority (41\%) were aged above 41 years, $(29.00 \%)$ were aged between from 31-40 and $>20$ were $(30.00 \%)$. In present study lap cholecystectomy (50\%) was the commonest procedure performed and was more frequently associated with port site complications. Fuller et al. reported similar observations [10]. Similarly Neudecker et al. had reported that port site complications were increased with a greater number of ports [11]. A study from Mangalore, Karnataka by Karthik et al. on 570 patients who underwent laparoscopic surgeries, reported that $3 \%$ had complications at port site during a minimum follow-up of three months; port site infection being most common $(1.8 \%)$ followed by port site bleeding $(0.7 \%)$, port site TB complications $(0.35 \%)$ and port site metastasis $(\mathrm{n}=$ 1, 0.175\%)[9]. Similarly in present study port site complication was seen in $2.50 \%$ patients followed by port site TB $1.00 \%$, Port site incisional hernia $0.50 \%$, among them bleeding $1.00 \%$ and port site metastasis $0.50 \%$ shown in study.No case of port site bleeding, discharge and hernia were reported in follow-up period [12]. In this Study the Port site surgeries were (49.50\%) participants had Lap Cholecystectomy, (17.50\%) patients had appendectomy, and $(13.00 \%)$ patients had Lap. Hernioplasty, (10.50\%) patients had Diagnostic laparoscopy, (7.00\%) had Lap ovarian cystectomy and $(2.50 \%)$ patients had Lap APR. Ahmed et al. and Memon et al. are also in agreement with the present study and reported lower infection rate respectively with laparoscopic surgeries $[13,14]$. However, Voitk et al. and Hamzaoglu et al. showed slightly higher rate of infections (9\% and $8 \%$ respectively) $[15,16]$. In present study port site bleeding was observed in $1 \%$ patients who is comparable to the reports [16]. Bleeding points can usually be identified and managed with electrocautery.

\section{CONCLUSION}

This is a descriptive study to analyses the morbidity associated with port site in laparoscopic surgeries (Basic and advanced) of the complications and their management. The study population consistof 200 and was carried out over two year of period. Complications encountered at port site were discharge, infection, bleeding, port site hernia and metastasis with discharge and infection being most common.

\section{REFERENCES}

1. Schwartz's Principles of Surgery Tenth Edition.

2. Yamamoto $\mathrm{S}$, Fujita $\mathrm{S}$, Akasu $\mathrm{T}$, Ishiguro $\mathrm{S}$, Kobayashi Y, Moriya Y. Wound infection after elective laparoscopic surgery for colorectal carcinoma. SurgEndosc. 2007; 21(12):2248-52. Epub 2007 May19.

3. Hackam DJ, Rotstein OD. Host response to laparoscopic surgery: mechanisms and clinical correlates. Can J Surg. 1998; 41(2): 10311. 
4. Bonjer HJ, Hazebroek EJ, Kazemier G, Giuffrida MC, Meijer WS, Lange JF. Open versus closed establishment of pneumoperitoneum in laparoscopic surgery. Br J Surg. 1997; 84(5):599602.

5. Mir IS, Ahmad M, Ahad B. Establishing pneumoperitoneum safely for laparoscopic surgeries. JK-Practitioner. 2005; 12(4):224-2267.

6. WA, AliSI, Shah NA, Khan M, Khan AS. The frequency of the port site $r$ infection in laparoscopic cholecystectomies. J Postgrad Med Inst. 2008; 22(1):66-70.

7. Sethi NK, Aggarwal PK, Duggal L, Sachar VP. Mycobacterium chelonae infection following laparoscopic inguinal herniorrhaphy. J Assoc Physicians India. 2003; 51:81-2.

8. Bhandarkar DS, Bhagwat S, Punjani R. Port site infection with mycobacterium chelonei following laparoscopic appendectomy. Indian J Gastroenerol 2001;20(6)247-48

9. Karthik S, Augustine AJ, Shibumon MM, Pai MV. Analysis of laparoscopic port site complications: A descriptive study. J Min Access Surg. 2013; 9:5964.

10. Fuller J, Ashar BS, Carey-Corrado J. Trocarassociated injuries and fatalities: An analysis of 1399 reports to the FDA. J Minim Invasive Gynecol. 2005; 12:302-7.

11. Neudecker J, Sauerland S, Neugebauer E, Bergamaschi R, Bonjer HJ, Cuschieri A, et al. The
European association for endoscopic surgery clinical practice guideline on the pneumoperitoneum for laparoscopic surgery. SurgEndosc. 2002; 16:1121-43.

12. Quilici PJ, Greaney EM, Quilici J, Anderson S. Trans abdominal preperitoneal laparoscopic inguinal herniorrhaphy: Results of 509 repairs. Am Surg. 1996; 62:849-52.

13. Dugg P, Shivhare P, Singh H, Mittal S, Kumar A, Munghate A. A Prospective Analysis of Port Site Complications in Laparoscopic Cholecystectomy. J Minim Invasive Surg Sci. 2014; 3(2): e17634.

14. Ahmad SA, Schuricht AL, Azurin DJ, Arroyo LR, Paskin DL, Bar AH. Complications of laparoscopic cholecystectomy: the experience of a universityaffiliated teaching hospital. J LaparoendoscAdvSurg Tech A. 1997; 7(1):29-35.

15. Memon W, Khanzada TW, Samad A, Laghari MH. Complications of laparoscopic cholecystectomy at Isra University Hospital, Hyderabad. Pak J Med Sci. 2009; 25(1):69-73.

16. Voitk AJ, Tsao SG. The umbilicus in laparoscopic surgery. SurgEndosc. 2001; 15(8):878-81.

17. Elashry OM, Nakada SY, Wolf JJ, Figenshau RS, McDougall EM, Clayman RV. Comparative clinical study of port-closure techniques following laparoscopic surgery. Journal of the American College of Surgeons. 1996 Oct;183(4):335-44. 